\title{
A study of maternal mortality due to non-obstetric causes
}

\author{
Tejal N. Kansara*, Tushar M. Shah, Foram R. Lalcheta
}

Department of Obstetrics and Gynecology, B. J. Medical College, Civil Hospital, Ahmedabad, Gujarat, India

Received: 08 March 2019

Accepted: 08 April 2019

\section{*Correspondence:}

Dr. Tejal N. Kansara,

E-mail: drtejalkansara12@gmail.com

Copyright: ( ) the author(s), publisher and licensee Medip Academy. This is an open-access article distributed under the terms of the Creative Commons Attribution Non-Commercial License, which permits unrestricted non-commercial use, distribution, and reproduction in any medium, provided the original work is properly cited.

\section{ABSTRACT}

Background: Pregnancy, although being considered a physiological state, carries the risk of serious maternal morbidity and at times mortality, due to various complications that may arise during pregnancy, labour or thereafter. The existing medical condition, infection, and surgical condition which is collectively called as non- obstetric cause pre disposes a women for more complication than a non-pregnant women, so much so that it can lead to maternal mortality. Thus, Pregnancy is more vulnerable state and present study was carried out to study, analyse and review various non-obstetrics causes of death of women during pregnancy or within 42 days of termination of pregnancy in Tertiary care centre.

Methods: This was an Observational study, conducted in the department of obstetrics and gynaecology, at a tertiary care hospital attached with medical college, from October 2016 to October 2018. The details of maternal deaths were collected from various departments with non- obstetric causes and analyzed.

Results: The total number of deliveries in my study period was 15,208 . There were 197 maternal mortality in our study period, of which 51 women died of non-obstetric causes. The most common cause of maternal mortality in our study was hepatic cause i.e. 33.33\% amongst which viral hepatitis was the most common cause followed by respiratory $(19.60 \%)$, infectious $(15.18 \%)$, heamoglobinopathy $(13.72 \%)$, cardiac $(5.88 \%)$, neurological $(5.88 \%)$, surgical $(5.88 \%)$ causes.

Conclusions: Looking into our study, maternal mortality can be reduced by identifying various different indirect medical causes which are preventable by proper pre-pregnancy evaluation for pre-existing comorbid conditions.

Keywords: Live births, Maternal mortality, Non-obstetric cause, Rural population, Viral hepatitis

\section{INTRODUCTION}

Maternal mortality is the death of a woman in relation to pregnancy. According to World Health Organization (WHO), "A maternal death is defined as the death of a woman while pregnant or within 42 days of termination of pregnancy, irrespective of the duration and site of pregnancy, from any cause related to or aggravated by pregnancy or its management” (ICD-10). ${ }^{1,2}$

Pregnancy and childbirth are joyful events but sometimes may land up with complications and death if risk factors are not identified and corrected at proper time. Death of a woman and mother is a tragic loss to the child, community and nation as whole. The young surviving children left motherless are unable to cope with daily living and are at increased risk of death. Also maternal mortality is just a tip of iceberg, for every woman who dies. Pregnancy, although being considered a physiological state, carries the risk of serious maternal morbidity and at times mortality, due to various complications that may arise during pregnancy, labour or thereafter. The existing medical condition, infection, and surgical condition which is collectively called as non- 
obstetric cause pre disposes a women for more complication than a non-pregnant women ,so much so that it can lead to maternal mortality. Thus, Pregnancy is more vulnerable state and present study was carried out to study all such non-obstetric causes of maternal mortality.

\section{According to WHO:}

- Everyday 830 women die from preventable causes related to Pregnancy and child-birth

- $\quad 99 \%$ deaths occur in Developing countries

- Maternal Mortality is higher in women living in rural areas and belong to poorer communities

- Young adolescents face a higher risk of complication and deaths as a result of pregnancy than other women

- Between 1990 and 2015, Maternal mortality dropped by about $44 \%$

- Between 2016 and 2030, as a part of the Sustainable Development Goals, the target is to reduce the Global maternal Mortality ratio to less than 70 per 1 , 00,000 live births.

Improving maternal Health is one of the eight United Nations millennium developmental goals that target the reduction of $75 \%$ in the maternal mortality. ${ }^{3}$

One target under sustainable development goal is to reduce the Global maternal mortality ratio to less than 70 per 1, 00,000 births.

Maternal death audits are conducted at institutional level, district level. Various delays in care are being identified. While the increased attention has clarified which interventions are more effective than others and promoted critical assessments of strategies, the main challenge remains the delivery of interventions to those areas of greatest need. The present study was conducted to Analyse and review various different non-obstetric causes leading to maternal deaths at a tertiary care centre, so that corrective steps can be taken.

To study, analyse and review various non-obstetrics causes of death of women during pregnancy or within 42 days of termination of pregnancy in tertiary care center.

The objective of this study was to know the incidence of maternal mortality due to non-obstetric causes in our Institute. To ascertain influence of factors such as age, location, parity, economic status, period of admission, Regular antenatal care, Outcome of pregnancy with NonObstetric causes of maternal deaths.

\section{METHODS}

This was an observational study, conducted in the department of obstetrics and gynaecology, at a tertiary care hospital attached with medical college, from October
2016 to October 2018. The details of maternal deaths were collected from various departments with nonobtetric causes and analysed with respect to the following parameters:

- Locality and socioeconomic status wise distribution of maternal deaths

- Literacy wise distribution of maternal deaths

- Parity wise distribution of maternal deaths

- Causes of maternal deaths.

Data collected from the cases were analyzed, computed and tabulated according to standard proforma.

Total No of Maternal deaths from October 2016 to October 2018 were 197, Out of which 51 cases were due to Non-Obstetric causes. All 51 cases which were analyzed computed and tabulated according to standard proforma. The details of number of live births of 2 year duration were collected which was 15,208.

\section{Inclusion criteria}

- $\quad$ All patients who expired while pregnant or within 42 days of termination of pregnancy

- Any gestational age or site of the pregnancy

- For Non- obstetric causes which were not related to Pregnant State (pregnancy, peuperium, labour) from interventions, omissions, incorrect treatment, or from a chain of events resulting from any of the above

- From causes that result from previous existing disease or from disease that developed during pregnancy and which was not due to direct causes, but which was aggravated by physiological effects of pregnancy.

\section{Exclusion criteria}

- Those who expired because of accidental or incidental causes were excluded from the study

- For obstetric causes which were related to Pregnant State (pregnancy, peuperium, labour) from interventions, omissions, incorrect treatment, or from a chain of events resulting from any of the above.

\section{RESULTS}

The study duration was from October 2016 to October 2018.The total number of deliveries in my study period were 15,208 .

There were 197 maternal mortality in our study period, of which 51 women died of non-obstetric cause which were included in the present study. Thus Maternal Mortality Ratio of our Tertiary Care centre was 130/1, 00,000 live births.

Approximately $64.70 \%$ mortality occurred in the age groups from 21-30. 
Table 1: Age wise distribution of the study population.

\begin{tabular}{|lll|}
\hline Age & Number & Percentage \\
\hline $15-19$ & 02 & 3.9 \\
\hline $20-24$ & 21 & 41.17 \\
\hline $25-29$ & 12 & 23.5 \\
\hline $30-34$ & 11 & 21.5 \\
\hline $35-40$ & 05 & 9.8 \\
\hline Total & 51 & 100 \\
\hline
\end{tabular}

Table 2: Relationship of economical status of the patient with maternal mortality.

\begin{tabular}{|lll|}
\hline Economic status & Number & Percentage \\
\hline Lower & 34 & 66.66 \\
\hline Middle & 17 & 33.33 \\
\hline Higher & 0 & 0 \\
\hline Total & 51 & 100 \\
\hline
\end{tabular}

In the present study, $66.66 \%$ of the patients were from lower socio-economical class, while rest $33.33 \%$ of the patients were from middle socio-economical class. There was no patient form the higher socio-economical class in the study.

Table 3: Relationship of residency with maternal mortality.

\begin{tabular}{|lll|}
\hline Population & Number & Percentage \\
\hline Urban & 15 & 29.41 \\
\hline Rural & 36 & 70.58 \\
\hline Total & 51 & 100 \\
\hline
\end{tabular}

In the present study, maximum numbers of the patients i.e. $70.58 \%$ were from rural region.

Table 4: Relationship of maternal mortality to mode of admission.

\begin{tabular}{|lll|}
\hline Cases & Number & Percentage \\
\hline Booked & 18 & 35.29 \\
\hline Emergency & 33 & 64.70 \\
\hline Total & 51 & 100 \\
\hline
\end{tabular}

$64.70 \%$ of the patients were unbooked/emergency cases which were brought to CHA in emergency hours, while only $35.29 \%$ were booked cases of CHA.

Table 5: Relationship of type of care provider from where patient was referred with maternal mortality.

\begin{tabular}{|lll|}
\hline Reference centre & Number & Percentage \\
\hline Private & 20 & 60.60 \\
\hline District & 10 & 30.30 \\
\hline Rural & 03 & 5.88 \\
\hline Total & 33 & 100 \\
\hline
\end{tabular}

Approximately $60.60 \%$ of the patients were referred from the private hospital across Gujarat and Rajasthan, followed by district hospital from various different cities i.e. 30.30 .

Table 6: Relationship of parity with maternal mortality.

\begin{tabular}{|lll|}
\hline Gravida & Number & Percentage \\
\hline Primi gravida & 18 & 35.29 \\
\hline Multi gravida & 28 & 54.90 \\
\hline Grand multi gravida & 05 & 9.80 \\
\hline Total & 51 & 100 \\
\hline
\end{tabular}

In the present study, $54.90 \%$ of the patients were multigravidas with a maximum number, followed by $35.29 \%$ were primigravida and $9.80 \%$ of the patients were grand multi gravida.

Table 7: Period at the time of admission.

\begin{tabular}{|lll|}
\hline Period & Number & Percentage \\
\hline Antenatal $<20$ weeks & 05 & 9.80 \\
\hline Antenatal $>20$ weeks & 31 & 60.78 \\
\hline Postnatal $<24$ hours & 07 & 13.72 \\
\hline Postnatal 24 hours to 1 week & 06 & 11.76 \\
\hline Postnatal 1 week to 42 days & 02 & 3.92 \\
\hline Total & 51 & 100 \\
\hline
\end{tabular}

Maximum numbers of patients were in the Antenatal $>20$ weeks group with 31 followed by postnatal $<24$ hours with 7 numbers.

Table 8: Mode of delivery.

\begin{tabular}{|lll|}
\hline Mode & Number & Percentage \\
\hline Undelivered & 14 & 27.45 \\
\hline Vaginal delivery & 21 & 41.17 \\
\hline Abortus & 05 & 9.80 \\
\hline LSCS & 10 & 19.60 \\
\hline Instrumental delivery & 01 & 1.96 \\
\hline Total & 51 & 100 \\
\hline
\end{tabular}

In our present study, 21 of the patients were delivered vaginally followed by 14 which were undelivered. 10 of the patient underwent LSCS followed by 5 of the patients in which abortion was done. In the study there was only 1 patient who underwent instrumental delivery.

Table 9: Outcome of pregnancy.

\begin{tabular}{|lll|}
\hline Outcome & Number & Percentage \\
\hline IUD & 16 & 31.37 \\
\hline Live birth & 16 & 31.37 \\
\hline Undelivered & 14 & 27.45 \\
\hline Abortus & 05 & 9.80 \\
\hline Total & 51 & 100 \\
\hline
\end{tabular}


In the present study, 16 of the patients were delivered being IUD and live birth with 16 each, followed by 14 in the undelivered group and 5 patients were aborted.

Table 10: Phase of labour at which the patient died.

\begin{tabular}{|lll|}
\hline Phase of labour & Number & Percentage \\
\hline Fourth stage of labour & 02 & 3.92 \\
\hline Antenatal <20 weeks & 01 & 1.96 \\
\hline Antenatal >20 weeks & 15 & 29.41 \\
\hline Postnatal <24 hours & 09 & 17.64 \\
\hline Postnatal 24hours to 1 week & 18 & 35.29 \\
\hline Postnatal 1 week to 42 days & 06 & 11.76 \\
\hline Total & 51 & 100 \\
\hline
\end{tabular}

In the present study, $35.29 \%$ of patients died when they were in postnatal period 24 hours to 1 week followed by $29.41 \%$ of patients in Antenatal $>20$ weeks.

Table 11: Maternal deaths in relation to time interval from delivery to death.

\begin{tabular}{|lll|}
\hline Delivery death interval & Number & Percentage \\
\hline$<24$ hours & 11 & 21.56 \\
\hline 24 hours to 1 week & 12 & 23.52 \\
\hline 1 week to 42 days & 13 & 25.49 \\
\hline Undelivered & 15 & 29.41 \\
\hline Total & 51 & 100 \\
\hline
\end{tabular}

In our study, delivery to death interval almost equal in all the 4 groups with maximum in undelivered group i.e. $29.41 \%$ and $25.49 \%$ in 1 week to 42 days time group.

Table 12: Cause of death.

\begin{tabular}{|lll|}
\hline Cause of death & Number & Percentage \\
\hline Hepatic causes & 17 & 33.33 \\
\hline Respiratory causes & 10 & 19.60 \\
\hline Cardiac causes & 03 & 5.88 \\
\hline Neurological causes & 03 & 5.88 \\
\hline Infectious causes & 08 & 15.68 \\
\hline Haemoglobinopathy & 07 & 13.72 \\
\hline Surgical causes & 03 & 5.88 \\
\hline
\end{tabular}

The most common cause of maternal mortality in our study was hepatic cause i.e. $33.33 \%$ amongst which viral hepatitis was the most common cause followed by hepatic encephalopathy with Acute Liver Failure. The second most common system involved was the respiratory system which was $19.60 \%$, of which $\mathrm{H} 1 \mathrm{~N} 1$ infection was the most common cause. Cardiovascular system and Central vascular system compromised $5.88 \%$ each.

\section{DISCUSSION}

Total numbers of maternal deaths from October 2016 to October 2018 were 197, out of which 51 cases were due to Non-Obstetric causes. All 51 cases which were analysed, computed and tabulated according to standard proforma. The details of number of live births of 2 year duration were collected which was 15,208.The largest number of maternal deaths, approximately $64.70 \%$ occurred in the age groups from 21-30, largely because those are the ages at which women are most likely to give birth, so efforts directed at this age group would most effectively reduce the number of deaths, which is in comparison to the study done by Puri A et al, which is $71.53 \% .{ }^{4}$ Although maximum number of maternal deaths occur in 20-34 age groups, it is necessary to identify the 'at risk' population to re-direct resources and fine-tune greater effectiveness in efforts to reduce maternal mortality Table 1 .

As per Table 2, in the present study, $66.66 \%$ of the patients were from lower socio-economical class, while rests $33.33 \%$ of the patients were from middle socioeconomical class. There was no patient form the higher socio-economical class in the study. This results were in close relation to the study done by Blank AK et al, which was $58 \%, 33 \%$ and $9 \%$ in lower, middle and upper socioeconomical class respectively. ${ }^{5}$ A study by Urmila $\mathrm{M}$ et al, had similar results to our present study i.e. $78 \%, 18 \%$ and $3 \%$ in lower, middle and upper socio-economical class. ${ }^{6}$ Poverty influences a woman's utilisation of health services and also has indirect effects on her general health by way of malnutrition. Women belonging to low socioeconomic strata are likely to be less privileged in the fields of education, nutrition, housing and antenatal care. Unawareness about contraceptive measures and high fertility rates also account for the mortalities in these women.

In the present study, maximum number of the patients i.e. $70.58 \%$ were from rural region (as per Table 3 ) which is in relation to the other studies done by Bellad MB et al, Urmila $\mathrm{M}$ et al, and Usharam et al, which were $69 \%, 76 \%$ and $75 \%$ respectively. ${ }^{6-8}$ Maternal mortality is higher in rural population because of illiteracy, inadequate antenatal visits, inaccessible emergency health care services, lack of transportation facilities and late referral. Many patients are referred very late, in critical condition, unaccompanied by health care worker. Emergency transport facility in the form of 108 is available but people living in rural areas fail to benefit from it because of lack of knowledge.

Booked patients are those who have taken at least 3 antenatal visits in our institute or any private or government hospital. As per Table 4, 64.70\% of the patients were unbooked/emergency cases which were brought to CHA in emergency hours, while only $35.29 \%$ were booked cases of CHA. Beyond doubt it is proven that unbooked emergency patients have more morbidity and mortality. The result of our study was in comparison to the study done by Bellad MB et al, and the UNICEF data which showed $69 \%$ and $66 \%$ of unbooked cases. ${ }^{7,9}$ However, findings of the studies done by Puri A et al, 
and Urmila $\mathrm{M}$ et al, were in near correlation were $92.3 \%$ and $89 \%$ of the patients were unbooked. ${ }^{4,6}$

Approximately $60.60 \%$ of the patient were referred from the private hospital across Gujarat and Rajasthan, followed by district hospital from various different cities i.e $30.30 \%$ (as per Table 5). In the study done by Bangal $\mathrm{VB}$ et al, the patient referred from private hospital were only $22 \%$ which is in contradiction to our study were almost $60 \%$ of the patients were referred from private hospital. $^{10}$

In the present study, $54.90 \%$ of the patients were multigravidas with a maximum number, followed by $35.29 \%$ were primigravida and $9.80 \%$ of the patients were grand multi gravid (as per Table 6). In the other studies done by Usharam et al, and Bangal VB et al, showed similar results to our present study with maximum in multigravida group i.e. $49.2 \%$ and $55.2 \%$ respectively. ${ }^{8,10}$ Probable explanation for higher percentage of deaths among multigravida patients is that too many and too close pregnancies together adversely affect the mother's health and have its roots in the social status of the woman. Multiparity increases the chances of anaemia, abnormal presentations, antepartum haemorrhage, post-partum haemorrhage, rupture uterus, less compliance to antenatal care.

As per Table 7, Maximum numbers of patients were in the Antenatal > 20 weeks group with 31 followed by postnatal $<24$ hours with 7 numbers.

In our present study, 21 of the patients were delivered vaginally followed by 14 which were undelivered. 10 of the patient underwent LSCS followed by 5 of the patients in which abortion was done. In the study there was only 1 patient who underwent instrumental delivery (as per Table 8). The findings were similar to the other study done by Nair $\mathrm{M}$ et al, with $46.5 \%$ of the patient being delivered vaginally. ${ }^{5}$

In the present study, 16 of the patients were delivered being IUD and live birth with 16 each, followed by 14 in the undelivered group and 5 patients were aborted (as per Table 9). The other studies done by Nair $\mathrm{M}$ at al, Bangal $\mathrm{VB}$ et al, and Puri et al, showed similar results with maximum in delivered group i.e. $79 \%, 81.5 \%$ and $63 \%$ respectively. ${ }^{4,10-12}$

In the present study, as per Table $10,35.29 \%$ of patients died when they were in postnatal period 24 hours to 1 week followed by $29.41 \%$ of patients in antenatal $>20$ weeks. Highest number of deaths in postpartum period indicates the need for continuous vigilance in postpartum period and prompt action in case of problems.

In our study, delivery to death interval almost equal in all the 4 groups with maximum in undelivered group i.e.
$29.41 \%$ and $25.49 \%$ in 1 week to 42 days time group (as per Table 11). The findings of our study were in correlation to the study done by Usharam et al, i.e. $24 \%$ and $29 \%$ in undelivered group and 1 week to 48 days group. ${ }^{8}$

According to Table 12, the most common cause of maternal mortality in our study was hepatic cause i.e. $33.33 \%$ amongst which viral hepatitis was the most common cause followed by hepatic encephalopathy with acute liver failure. Acute viral hepatitis is a major public health problem in the developing countries. Most of the cases of Hepatitis in India have been attributed to Hepatitis E, for which it is an endemic zone. This infection can spread in epidemics or sporadically, especially during the warm and rainy weather seasons. The presentation of Hepatitis E during pregnancy may range from the asymptomatic to fatal in different endemic areas.

Various reports evaluating etiological spectrum in individuals with acute hepatitis during both epidemic and sporadic settings indicate three distinct observations in India: ${ }^{12-14}$

- $\quad$ HEV is the commonest cause of AVH (Acute Viral Hepatitis) in both sporadic and epidemic settings

- The frequency of HEV as the cause of AVH is significantly higher among pregnant females than in non-pregnant females and males

- The frequency of ALF (Acute Liver Failure) is significantly higher in pregnant females than in nonpregnant females and males with HEV infection.

In the other studies done by Bangal VB et al, and Puri et al, showed that the leading indirect cause of maternal mortality was hepatitis which was in relation to our present study. ${ }^{4,10}$

The second most common system involved was the respiratory system which was $19.60 \%$, of which H1N1 infection was the most common cause. Findings from the study done by Rojas-Suarez $\mathbf{J}$ et al, suggest that none of the non survivors of $\mathrm{H} 1 \mathrm{~N} 1$ disease had received prenatal influenza vaccine and most had a delay in the initiation of antiviral therapy after the development of symptoms and profound hypoxemia with challenges related to mechanical ventilation in all cases. ${ }^{15}$ Despite the known epidemic (after mid-2009), one-third of patients failed to receive antiviral therapy. Women who were pregnant at the time of H1N1 diagnosis and died from the disease had high rates of stillbirths and preterm births.

Cardiovascular system and central vascular system compromised $5.88 \%$ each. In the present study, 8 patients died due to infectious diseases, of which 5 patients had positive falciparum malaria infection, two patients were immune-compromised and one had PUO associated with septicaemia. There were 7 patients with severe anaemia and with sickle cell crisis. There were 3 patients in the 
present study that died due to surgical cause in form of sigmoid colon perforation, cecal perforation and sigmoid volvulus respectively.

Table 13: Comparison of cause of death to other studies.

\begin{tabular}{|llll|}
\hline Cause & This study & Puri et al $^{4}$ & Bangal VB et al $^{10}$ \\
\hline Hepatic causes & $33.3 \%$ & $15 \%$ & $36.3 \%$ \\
\hline Respiratory causes & $19.60 \%$ & $9.1 \%$ & - \\
\hline Cardiac causes & $5.88 \%$ & $1.6 \%$ & $22.7 \%$ \\
\hline Neurological causes & $5.88 \%$ & $0.8 \%$ & $22.7 \%$ \\
\hline Haemoglobinopathy & $13.72 \%$ & $14.1 \%$ & $4.5 \%$ \\
\hline Infectious diseases & $15.68 \%$ & $25 \%$ & $13.6 \%$ \\
\hline Surgical Cause & $5.88 \%$ & $1.6 \%$ & - \\
\hline
\end{tabular}

\section{CONCLUSION}

We conclude from our studies that out of 197 total maternal deaths. 51 Maternal deaths were due to nonobstetric causes. That was $25.8 \%$ out of total maternal deaths and most common non- obstetric cause of maternal death is Hepatitis (33.3\%). Pregnancy itself is "Immuno-compromised" state that makes pregnant women more susceptible to infections. Previous existing condition or infection that develop during pregnancy which is not a result of direct obstetric cause, but which is aggravated by physiologic effect of pregnancy complicates the obstetric conditions leading to maternal mortality. The complications leading to maternal death can occur without warning at anytime during pregnancy and childbirth. Looking into our study various different indirect medical causes in descending order of frequency like hepatitis, respiratory disorders, cardiovascular disorders, anaemia and infectious/ communicable diseases. All these are preventable by proper prepregnancy evaluation for pre-existing comorbid conditions. Rest can be decreased by identifying high risk pregnancies and appropriate intrapartum and postpartum monitoring. If the GDP of our country will grow, the economic standards will increase, which will help in reducing maternal mortality by proper allocation of resources to individual as a whole.

\section{Funding: No funding sources}

Conflict of interest: None declared

Ethical approval: The study was approved by the Institutional Ethics Committee

\section{REFERENCES}

1. World Health Organization. Trends in maternal mortality: 1990 to 2008. Available at: http://whqlib.who.int/publications/2010/9789241150 0265_eng.pdf. Accessed August 7, 2011.

2. WHO. International classification of diseases and related health problems, 10th revision. Geneva: World Health Organization. 1992.
3. United Nations Development Programme. Millennium Development Goals. Available at: http://www.undp.org/mdg/goa15.shtml. Accessed August 7, 2011.

4. Puri A, Yadav I, Jain N. Maternal mortality in an urban tertiary care hospital of North India. The $\mathrm{J}$ Obstet Gynecol India. 2011:280-5.

5. Blanc AK, Winfrey W, John R. New findings for maternal mortality age patterns: aggregated results for 38 countries. PLoS One. 2013;8(4):e59864.

6. Mahala U, Prakash O, Mehta S, Sharma M. Maternal mortality at tertiary care hospital in Rajasthan: a 10 year review. IOSR J Dent Med Sci. 2017;16(6):8992.

7. Bellad MB, Vidler M, Honnungar NV, Mallapur AS, Ramadurg U. Maternal and newborn health in Karnataka State, India: the community level interventions for preeclampsia (CLIP) trial's baseline study results. PLOS ONE. 2017; doi:10.1371/journal.pone.0166623.

8. Montgomery AL, Ram U, Kumar R, Jha P. The million death study collaborators maternal mortality in India: causes and healthcare service use based on a nationally representative survey. PLoS ONE. 2014;9(1):e83331.

9. WHO, UNICEF, UNFPA, World Bank Group and the United Nations Population Division. Trends in maternal mortality: 1990 to 2015. WHO /RHR/15.23. The Lancet. 2015. Available at: http://dx.doi.org/10.1016/ S0140-6736(15)00838.

10. Bangal VB, Giri PA, Garg R. Maternal mortality at a tertiary care teaching hospital of Rural India: a retrospective study. Int $\mathrm{J}$ Biol Med Res. 2011;2(4):1043-6.

11. Nair M, Choudhury MK, Choudhury SS, Kakoty SD, Sarma UC, Webster P, et al. Association between maternal anaemia and pregnancy outcomes: a cohort study in Assam, India. BMJ Glob Health. 2016.

12. Beniwal M, Kumar A, Kar P, Jilani N, Sharma JB. Prevalence and severity of acute viral hepatitis and fulminant hepatitis during pregnancy: a prospective 
study from north India. Indian J Med Microbiol. 2003;21:184-5.

13. Rasheeda CA, Navaneethan U, Jayanthi V. Liver disease in pregnancy and its influence on maternal and fetal mortality: a prospective study from Chennai, Southern India. Eur J Gastroenterol Hepatol. 2008;20:362-4.

14. Patra S, Kumar A, Trivedi SS, Puri M, Sarin SK. Maternal and fetal outcomes in pregnant women with acute hepatitis E virus infection. Ann Intern Med. 2007;147:28-33.
15. Rojas-Suarez J, Paternina-Caicedo A, Cuevas L, Angulo S, Cifuentes R, Parra E. Maternal mortality due to pandemic influenza A H1N1 2009 virus in Colombia. J Perinat Med. 2014;42(1):19-26.

Cite this article as: Kansara TN, Shah TM, Lalcheta FR. A study of maternal mortality due to nonobstetric causes. Int J Reprod Contracept Obstet Gynecol 2019;8:2027-33. 